\title{
Normal Rabbit Aqueous Humour, Fibronectin, and Fibroblast Conditioned Medium are Chemoattractant to Tenon's Capsule Fibroblasts
}

\author{
J. P. JOSEPH, I. GRIERSON and R. A. HITCHINGS \\ London
}

\begin{abstract}
Summary
Some of the chemotactic and chemokinetic properties of rabbit Tenon's fibroblasts were examined in a 48-well micro-chemotaxis chamber. Normal rabbit aqueous humour, fibronectin, and fibroblast conditioned medium were used in the assay, and all were shown to be chemoattractant. In addition, aqueous humour was shown to be powerfully chemotactic. Since the failure of human trabeculectomies is associated with migration of fibroblasts to the operation site, the study of the chemoattractant influences acting on these cells may allow manipulation of their behaviour in order to influence favourably the outcome of surgery.
\end{abstract}

Of the trabeculectomies that fail the majority do so because of fibrosis at the operation site. ${ }^{\prime}$ Factors leading to fibrosis and the role of aqueous humour in the success or failure of the procedure are poorly understood. Teng et al. ${ }^{2}$ proposed that aqueous had a degenerative effect on collagen. Kornblueth et al. ${ }^{3}$ proposed that there is an inhibitory factor for fibroblast proliferation and iris tissue present in aqueous humour, while Herschler postulated the existence of an inhibitory factor for fibroblasts present in normal aqueous humour and absent in glaucomatous aqueous..$^{4.5 .6 .7}$ In a model of failing fistulising surgery in the rabbit, Miller et al. ${ }^{8}$ have shown that fibroblast migration to the operation site, together with fibroblast proliferation, play a fundamental role in the obstruction of the fistula. In spite of work having been done on fibroblast antiproliferative agents, ${ }^{9}$ little attention has been paid to the chemotaxis of these cells in this context. Although fibroblast chemotaxis has been studied at other sites in the body, evidence suggests that fibroblasts in different locations behave differently. ${ }^{10}$ The present study was undertaken to elucidate some of the chemoattractant influences acting on ocular fibroblasts and to determine the chemotactic activity of normal rabbit aqueous humour.

\section{Material and Methods}

Fibroblasts Biopsies of Tenon's capsule and sclera were taken from 5 New Zealand White rabbits. These primary explants were placed in $25 \mathrm{~cm}^{2}$ plastic tissue culture flasks (Sterilin) and incubated at 37 degrees $\mathrm{C}$ in 5 per cent $\mathrm{CO}_{2} / 95$ per cent air. The cultures were fed twice weekly with F10 medium with 10 per cent new born calf serum. containing 100 units per $\mathrm{ml}$ of streptomycin and penicillin, and 0.25 units per $\mathrm{ml}$ of amphotericin B. Cells grown from the primary explants reached confluence within 3 to 4 weeks, whereupon the cultures from the five different animals were bulked

From The Institute of Ophthalmology, London, and Moorfields Eye Hospital.

Correspondence to: Dr. Ian Grierson, The Institute of Ophthalmology, 17-25 Cayton Street, London EC1V9 9AT.

This paper is based on a poster displayed at the Ophthalmological Society of the United Kingdom Annual Congress in April 1987. 


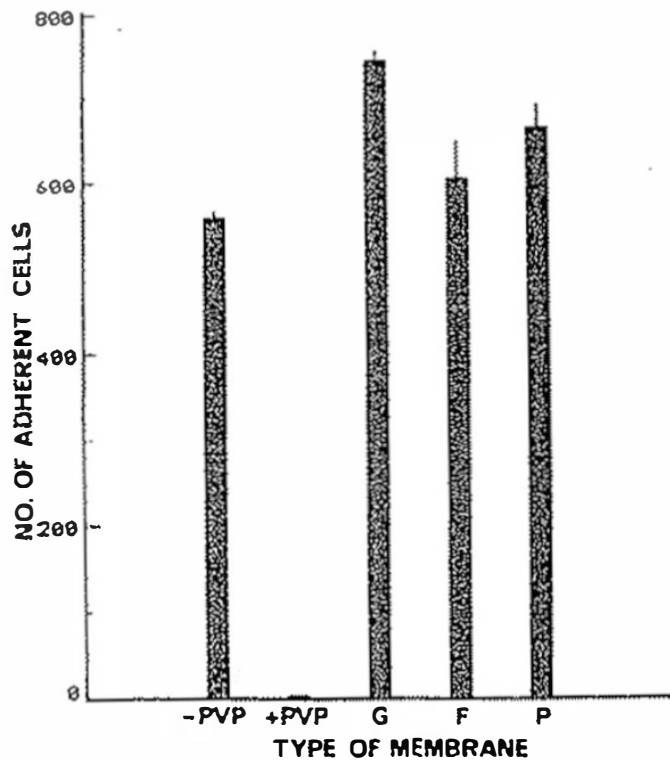

Fig. 1. Graph showing the adherence race of rabbit Tenuri's fibroblusis 10 various kinds of polycarbonare membranes: $-P V P=$ Poljovinyl-Pyrallidine Freei $+P V P=$ With Polyvinyl. Pyrollidine; $G=$ Gelatin and PVP:F = Fibronectin and PVP; $P=$ Poly-L-Lysine and PVP. The same number of cells was added 10 chambers containing the $S$ types of membrane. After of hours incubation. the cells arrached to the membranes in $201.000 \times$ fields were coumted. Four indivithul chambers were counted for each membrane. Bais show the mean: lines the S.E.H.

together and passaged. Split ratios varied from $1-4$ to $1-10$. Tenon's fibroblasts were used between passages 2 and 4 in the chemotaxis experiments; scleral tibroblasts were used to prepare conditioned medium at 2 nd passage.

Chemolaxis Chemotaxis was undertaken in a 48-well micro-chemotaxis chamber (Neuro Probe, Cabin John, Maryland), based on the original Boyden Chamber." Polycarbonate membranes $25 \times 80$ $\mathrm{mun}, 10 \mu \mathrm{m}$ thick and with pores $8 \mu \mathrm{m}$ in diameter were used (Nuclenpore, Pleasanton, California). Membranes are available with or without the wetting agent polyvinyl-pyrrolidine (+PVP or - PVP). As obtained from the manufacturer, membranes with polyvinyl-pyrrolidine tvould not allow satisfactory adherence of tibroblasts and the morphology of cells adherent to the PVP tree membranes was highly abnormal. Accordingly, membranes with PVP were treated in the following way to promote the adherence of the cells:

(a) Gelatin. Membranes were placed in a glass heaker containing 0.5 per cent acetic acid as 50 degrees $C$ for 20 minutes. They were then washed twice in glass distilled water, following which they were placed in a solution containing $5 \mathrm{mg} / \mathrm{l}$ Porcine gelatin type 1,300 bloom (Sigma) in distilled water at 100 degrees $C$ for one hour. The membranes were then air dried. and subsequently placed in an oven at 100 degrees $C$ for one hour. ${ }^{12}$

(b) Fibronectin. Membranes were placed in a solution of $100 \mu \mathrm{g} / \mathrm{ml}$ of bovine hibronectin (Sigma) in distilled water for 30 minutes and then air dried. ${ }^{13}$

(c) Poly-L-Lysine. Membranes were soaked in 1 per cent Poly-L-Lysine (MW> 300,000 Sigma) in distilled water for two hours and then washed in distilled water for two hours. "s

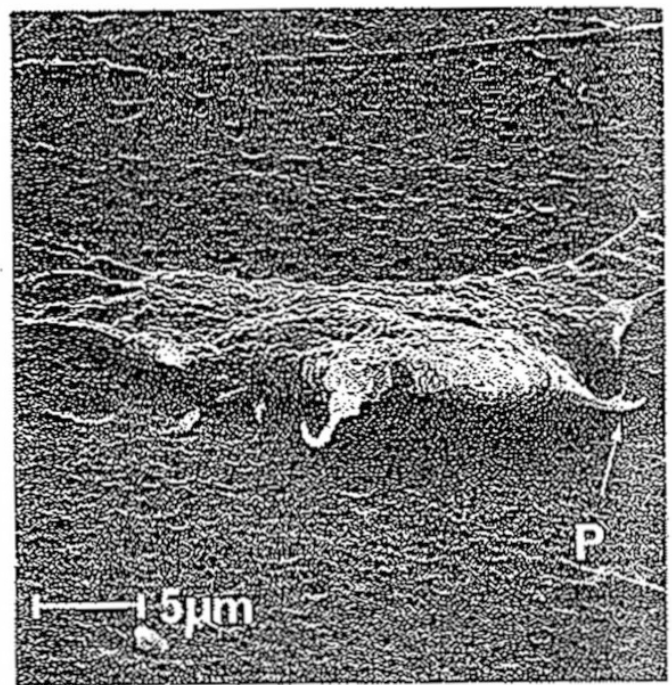

Fig. 2(a). Scanning electran micrugraph of a Tenon's fibroblast with a process passing into an 8 fun diameiter pore $(P)$ in the polycarbonne nembrome.

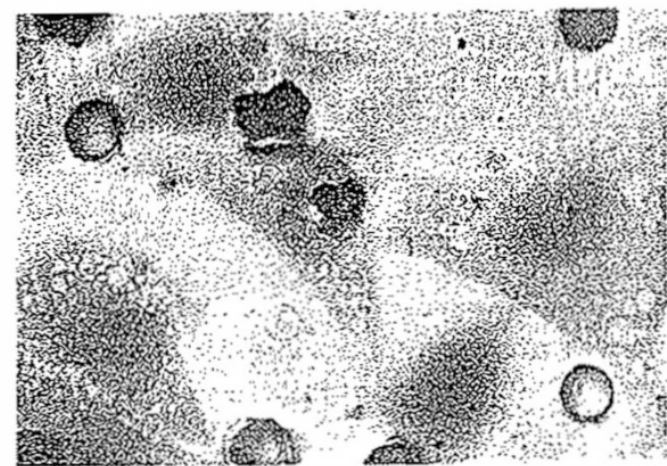

Fig. 2(b). Light micrograph showing cells that hase successfully migrated through the pores and ure adherent ro the membrane. Blurs in she hackgy-ound are cells adherent to the membrane that have not yet migrmed. 


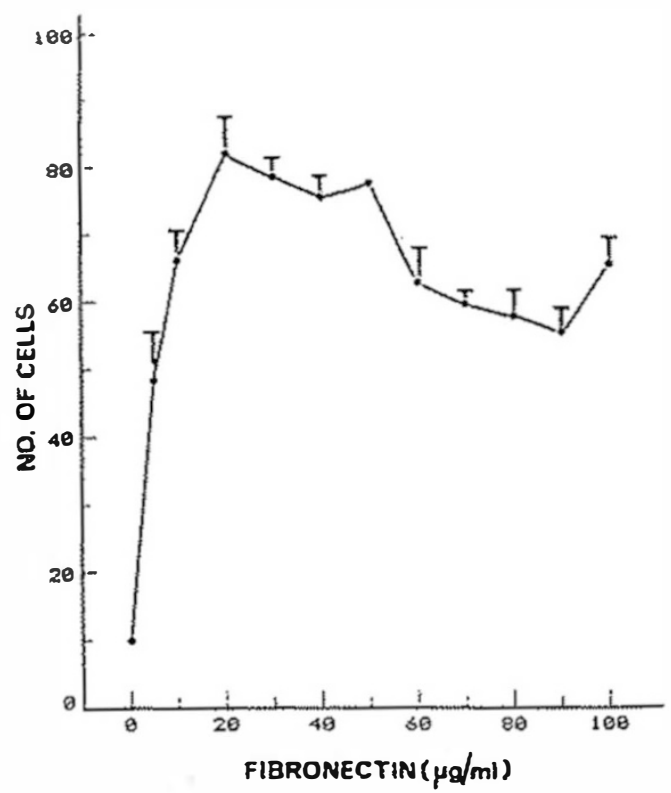

Fig. 3. Dose response curve of fibronectin. Cells that have successfully migrated through the pores have been counted in $201,000 \times$ fields $\left(0.54 \mathrm{~mm}^{2}\right)$. Each point is the mean of three chambers. Bars are standard errors of the mean.

Membranes with PVP, treated with gelatin, allowed the greatest fibroblast adherence rate (Fig. 1) as well as normal fibroblast morphology. Accordingly, gelatinised membranes were used in all the chemoattraction experimenis. All membranes were used shiny side up in the chemotaxis chamber, according to the manufacturer's instructions. Chemoattractants were added to the lower chambers of the array and dilutions were made with serum free $F 10$ medium.

The fibroblasts were used just on becoming confluent, approximately 4-7 days after passaging. The cells were removed from their culture flasks by brief exposure ( 3 minutes) to 0.25 per cent Trypsin and 0.02 per cent EDTA. Exposure to trypsin for longer than this leads to a reduction of chemotactic activity. 12 Cells were suspended in $10 \mathrm{ml} \mathrm{F10} \mathrm{with} 10$ per cent new born calf serum, and centrifuged at $300 \mathrm{~g}$ for 10 minutes, following which they were washed once with serum free F10. Cell counts were made using a Coulter counter, and they were finally suspended at a concentration of $7 \times 10^{\mathrm{s}} \mathrm{cell} / \mathrm{s} / \mathrm{ml}$. Fifty $\mu \mathrm{l}$ of cell suspension was added to each of the top chambers of the array.

The micro-chemotaxis chamber was incubated at 37 degrees $C$ in 5 per cent $\mathrm{CO}_{2} / 95$ per cent air for 4 hours. The polycarbonate membrane was removed from the chamber, placed in 100 per cent ethanol for 30 seconds, air dried, and stained with haematoxylin.

Membranes were mounted on a glass slide and then examined with a light microscope at 1,000x magnification (Olympus, Tokyo). The number of cells that had migrated through the pores, towards the chemoattractant, was estimated by counting cell nuclei on the distal side of the membrane. Twenty fields were examined for each of the 48 chambers. This represented $0.54 \mathrm{~mm}^{2}$ or $1 / 15$ th of the membrane corresponding to each chamber. A membrane was also prepared for scanning and transmission electron microscopy (Fig. 2).

Fibronectin Bovine fibronectin (Sigma) was stored at - 20 degrees $C$ until used. In all chemotaxis assays of fibroblast conditioned medium and aqueous humour, fibronectin was run as a positive

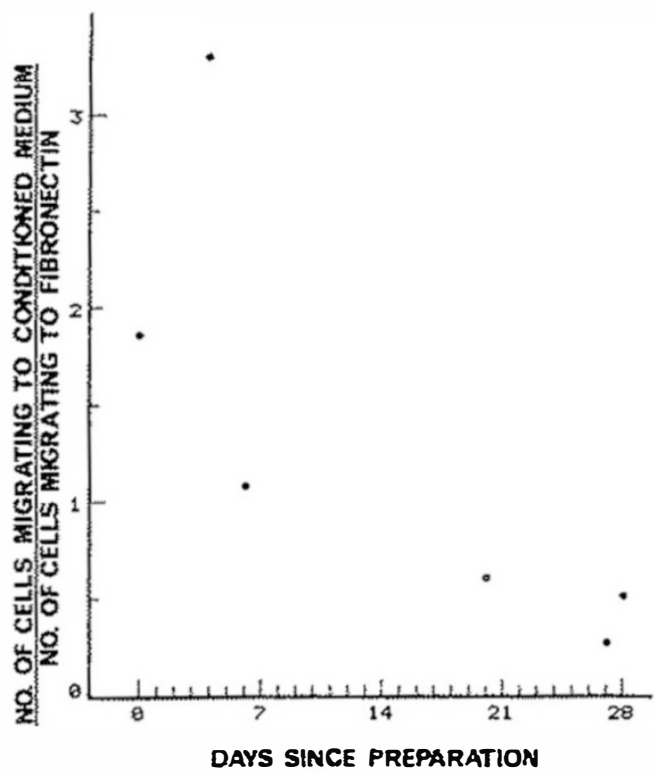

Fig. 4. Graph showing the decline in the relative chemoattractiveness of fibroblast conditioned medium over lime. The medium was stored at -20 degrees $C$. The chemoattractive activity ivas measured as the ratio of the number of cells in 20 1,000x fields inigrating 10 fibroblast conditioned medium versus the number of cells in 201,000x fields migrating 10 an optimal dose of fibronectin. Initially fibroblast conditioned medium was 2 to 3 times as active as fibronectin; after storage for 28 days this had reduced 10 about 0.5 times the activity. Each point is the mean of 3 observations. Sinndard errors of the mean for fibroblast conditioned medium were all less than 16 per cent. 
control, with serum free $\mathrm{F} 10$ medium as a negative control.

Fibroblast Conditioned Medium A confluent culture of scleral fibroblasts was washed three times with phosphate buffered saline. It was then washed twice with $10 \mathrm{ml}$ of serum free F10 medium, and a further $5 \mathrm{ml}$ of this medium was incubated in the flask for 24 hours. This fibroblast conditioned medium was centrifuged at $300 \mathrm{~g}$ for ten minutes to remove floating cells. The supernatant was then aliquoted and frozen at $\mathbf{- 2 0}$ degrees $\mathrm{C}$ until used in the chemotaxis assay. 15

Agueous Humour Nine New Zealand White rabbits (18 eyes) weighing approximately $2 \mathrm{~kg}$ were used in the study. The rabbits were sacrificed by an overdose of barbiturates. Immediately post mortem, a paralimbal transcorneal paracentesis was made using a $25 \mathrm{G}$ needle and the aqueous humour was allowed to drip from the end of the needle Approximately $100 \mu \mathrm{l}$ was obtained from each animal. The aqueous was either used immediately or was stored at -20 degrees $C$. Stored in this way the

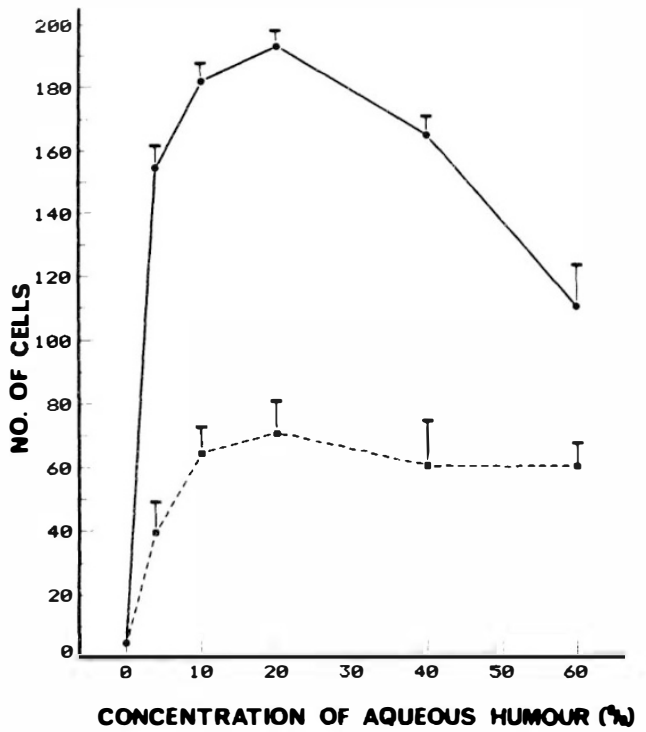

Fig. 5. Graph showing the chemoattractive activity of normal rabbit aqueous humour (-) and of similar aqueous humour that has been boiled for 5 minutes (-- -). The cell count was made in $201,000 \times$ fields. Each point is the mean of four chambers. The normal aqueous was taken from one eye of 2 rabbits, while the boiled aqueous was derived from their other eyes. Bars are I S.E.M. $20 \mu \mathrm{g} / \mathrm{ml}$ fibronectin caused 90 cells to migrate. For 20 per cent aqueous, boiling reduces the chemoattractiveness activity by about 65 per cent $(p=0.014$ Mann-Whitney U (est). aqueous retained its chemotactic activity for at least 6 weeks

\section{Results}

Fibronectin is chemoattractant to rabbit Tenon's fibroblasts with an optimal dose of 20 $\mu \mathrm{g} / \mathrm{ml}$ (Fig. 3). At doses higher than this there is a slow decrease in effect. This continues to occur between $10(0 \mu \mathrm{g} / \mathrm{ml}$ and $1,(0)(0) \mu \mathrm{g} / \mathrm{ml}$ (data not shown). The optimal dose of 20) $\mu \mathrm{g} / \mathrm{ml}$ fibronectin has been used as a positive control in subsequent experiments. Boiling a solution containing this dose for 5 minutes is sufficient to deactivate the chemoattractive effect.

Scleral fibroblast conditioned medium is also strongly chemoattractant to Tenon's fibroblasts. When the conditioned medium was first prepared it was 2 to 3 times as potent in its chemoattractive effect as an optimal dose of fibronectin. After storage for 20 days at -20) degrees C, fibroblast conditioned medium was approximately half as potent as fibronectin (Fig. 4)

The response of the cells to the chemoattractants varies considerably depending on the confluency of the culture, the time since passaging, the time since the last feeding, and probably a number of other undefined factors. This makes comparison of results obtained on different days unreliable, in spite of using positive and negative controls in each run. However, all the specimens of normal rabbit aqueous humour were strongly chemoattractant, and the effect seen was always considerably greater than that of the optimal dose of fibronectin. An initial dose response curve was obtained using the aqueous from two eyes, as seen in Figure 5, where it is apparent that the optimal concentration is between 10 per cent and 20 per cent aqueous humour. This dose response curve has been confirmed four times. Using a smaller range of concentrations of aqueous humour it has been possible to compare 14 specimens ( 8 different animals) simultaneously (Fig. 6).

In a Zygmond-Hirsch ${ }^{17}$ chequer board analysis of a sample of aqueous humour (Fig. 7), it appears that the aqueous exerts a predominantly chemotactic effect, while at low concentrations there is a chemokinetic effect, which falls off at higher doses. Boiling rabbit 


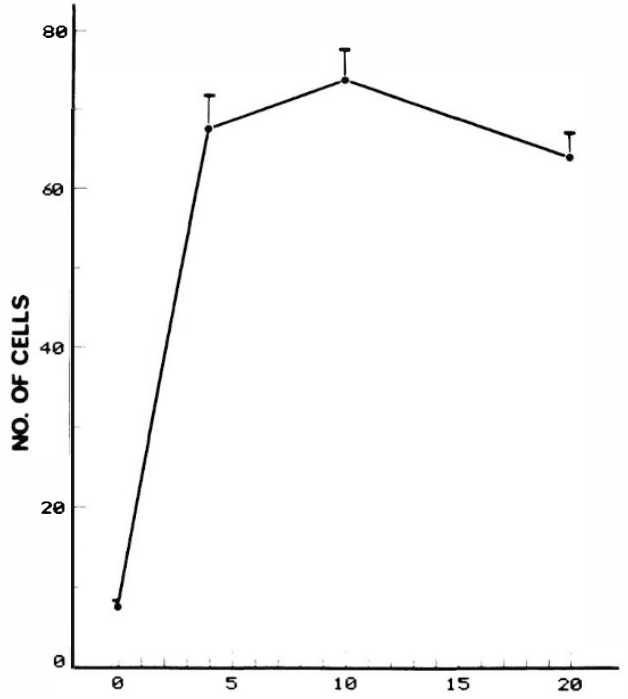

CONCENTRATION OF AQUEOUS HUMOUR (\%)

Fig. 6. Dose response curve of chemoattractive activity of normal rabbit aqueous humour. At 0 percent aqueous (serum free FlO medium), point is the mean of 3 observations. Other points are the means of 14 aqueous specimens taken from 8 rabbits and run simultaneously in a single 48-well chemotaxis chamber. Cells have been counted in $201,000 \times$ fields for each sample. Bars are I S.E.M. $20 \mu \mathrm{g} / \mathrm{ml}$ fibronectin caused 4.5 cells to migrate. 4 per cent aqueous causes a highly significant increase in the number of cells migrating across the membrane $(p<0.001$ Student's t test $d f=1.5)$. There is no significant difference between the effect of 10 per cent aqueous and 4 per cent aqueous $(0.1<p<0.5)$ or between the effect of 20 per cent aqueous and 4 per cent aqueous $(P>0.5)$.

aqueous for 5 minutes still leaves it with a substantial chemoattractant effect (Fig. 5). Analysis of the chequer board for boiled aqueous, from the same animal as in Figure 7 , shows that the predominant effect is still chemotactic, although this is reduced, and there is a similar chemokinetic effect (Fig. 8).

\section{Discussion}

Fibronectin is chemoattractive to rabbit Tenon's fibroblasts. This is relevant since fibronectin occurs in healing wounds ${ }^{18}$ and is responsible for the adherence of the cells to the connective tissue matrix. ${ }^{19}$ Fibronectin also occurs in aqueous humour, ${ }^{20}$ and is probably one of numerous factors responsible for the migration of fibroblasts towards a healing trabeculectomy. Although we found that
$20 \mu \mathrm{g} / \mathrm{ml}$ was the optimal dose of fibronectin, the literature is confused on this and optimal doses of $1.2 \mu \mathrm{g} / \mathrm{ml},{ }^{16} 20 \mu \mathrm{g} / \mathrm{ml}^{21}$ and $100 \mu \mathrm{g} /$ $\mathrm{ml}^{15.22}$ have been mentioned. This may relate to differences in the measurement or preparation of fibronectin, as well as to the source of the fibroblasts used in the assay, since fibroblasts of diverse origins may respond differently to the same chemical mediator. ${ }^{10}$

Fibroblast conditioned medium is also a chemoattractant for rabbit Tenon's fibroblasts. This is interesting as it helps to explain the self perpetuating nature of scarring. Once a few fibroblasts have been attracted to a healing trabeculectomy, they are able to call up reinforcements, and the process continues. Some of the factors known to be synthesised by fibroblasts are collagen, fibronectin, and proteoglycans. The former two are known to be chemotactic to further fibroblasts. ${ }^{15,16.21 .23}$ However, Mensing et al. proposed that there is another, as yet unidentified, chemotactic

\section{UPPER CHAMBERS}

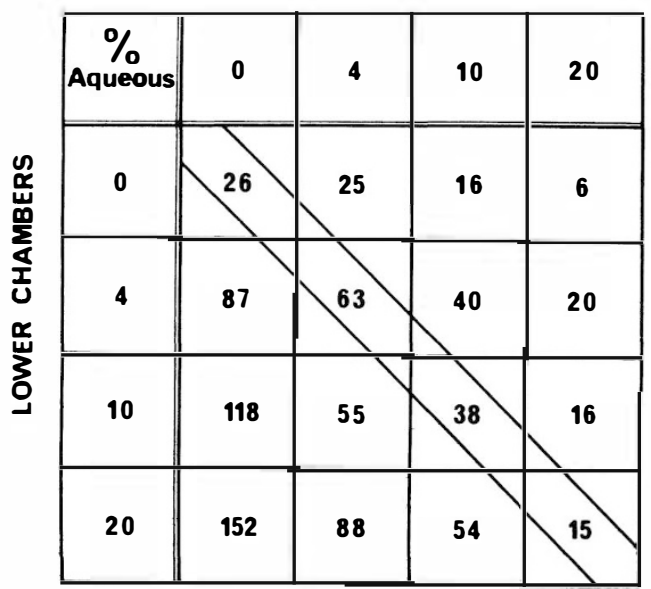

Fig. 7. A chequer board analysis of normal rabbit aqueous humour. Aqueous humour is added to both the upper and lower chambers of the array, such that the Tenon's fibroblasts are exposed to (a) a positive gradient of the chemoattractant, (b) a negative gradient, and (c) no gradient but merely an increased concentration of the chemoattractant, equal in both the upper and lower chambers (between the diagonal lines). Normal aqueous humour is powerfully chemotactic (cf. optimal dose of fibronectin which caused 62 cells to migrate) but at low doses there is a moderate chemokinetic effect which diminishes at higher doses. A similar result has been seen in chequer boards done on 3 other aqueous specimens. 
UPPER CHAMBERS

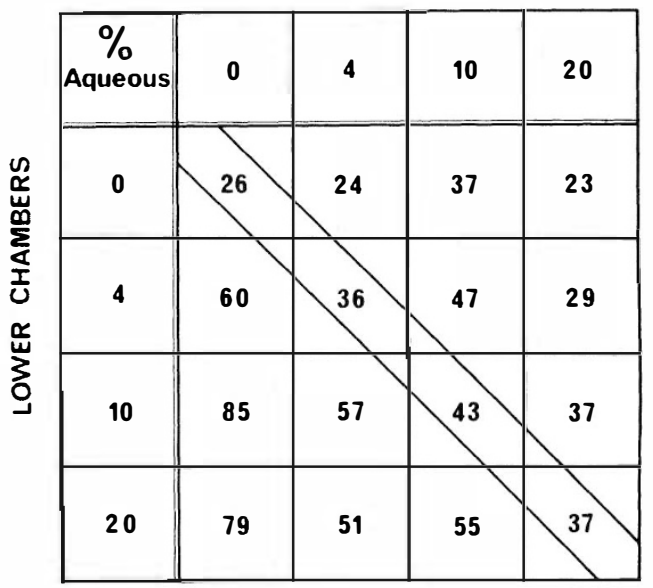

Fig. 8. A chequer board analysis of aqueous humour derived from the other eye of the rabbit in Figure 7 and run simultaneously in the same experiment. This aqueous has been boiled for 5 minutes. The aqueous retains much of its chemotactic activity, with similar chemokinetic activity.

factor(s) in fibroblast conditioned medium besides collagen and fibronectin. ${ }^{15}$

Fibronectin and fibroblast conditioned medium are only two of numerous factors that have been demonstrated to be chemotactic. using non-ocular fibroblasts. These factors include elastin, ${ }^{24}$ tropoelastin, ${ }^{14}$ collagen, ${ }^{2.3}$ fibronectin peptides, ${ }^{21}$ platelet derived growth factor, ${ }^{25}$ leukotriene $\mathrm{B}_{4},{ }^{26}$ coagulation products, ${ }^{27}$ lymphokines, ${ }^{28}$ and activated complement..$^{29}$ Doubtless many of these substances also are chemotactic for ocular fibroblasts. It follows that any drug used to inhibit the process of fibroblast chemoattraction will have to be directed at the locomotory function of the cells, since a block against any one chemoattractant will be easily circumvented.

Normal rabbit aqueous humour is strongly chemotactic to rabbit Tenon's fibroblasts. This was confirmed in a chequer board analysis. ${ }^{17}$ Although the rabbit blood-aqueous barrier is very easily disrupted, the fact that the moderate chemokinetic effect seen at low concentrations of aqueous was reduced at 20 per cent aqueous, mitigates against a disruption of the barrier. Since protein can be chemokinetic one would anticipate a far greater chemokinetic effect which would increase with higher concentrations of aqueous, had the blood aqueous-barrier been disrupted. ${ }^{30}$ The aqueous was also removed immediately post mortem and was allowed to drip out of the eye under the influence of the intra-ocular pressure; this would also reduce the possibility of disrupting the blood-aqueous barrier.

We have found that boiling fibronectin containing solutions for 5 minutes is sufficient to deactivate the chemoattractant effect. Boiled aqueous humour retains a proportion of its chemoattractant activity which is confirmed by chequer board analysis, to be predominantly chemotactic. The reduction in the chemotactic activity caused by boiling is slightly more than can be accounted for by the effect of removing $20 \mu \mathrm{g} / \mathrm{ml}$ of fibronectin. The fibronectin concentration of bovine eyes has been measured at $2.46 \mu \mathrm{g} / \mathrm{ml}^{20}$ or about 100 th of the level in human blood. Fibronectin is also known to be produced by corneal endothelial cells ${ }^{31}$ and meshwork cells in tissue culture. ${ }^{32}$

$2.46 \mu \mathrm{g} / \mathrm{ml}$ is about a $\log$ unit lower than the optimal concentration of fibronectin that we found. However, as mentioned above, there are difficulties in estimating the true optimal dose of fibronectin. So, a component of the chemotactic activity of normal rabbit aqueous humour may be accounted for by fibronectin. Accurate measurement of the fibronectin content of rabbit aqueous humour will be needed to clarify this. However, what accounts for the rest of the chemotactic activity of rabbit aqueous humour is at present unknown. Some chemoattractants, e.g. platelet derived growth factor retain their chemotactic properties after boiling for 5 minutes, ${ }^{33}$ and this substance could possibly contribute to the chemoattractiveness of normal rabbit aqueous humour.

Given that rabbit aqueous humour is powerfully chemotactic to rabbit Tenon's fibroblasts, it is surprising that it has not been found to be a chemoattractant for macrophages $^{34}$ and neutrophils. ${ }^{30}$ In addition, Tapper et al. ${ }^{35}$ examined the migration of capillary endothelial cells in response to normal rabbit aqueous humour, and found no stimulatory activity.

Rabbit eyes are known to exhibit a marked inflammatory response and to heal up a fistulising wound within 17 days. ${ }^{8}$ A major 
part of this healing response may be attributable to the intrinsic chemotactic activity of normal aqueous humour, for fibroblasts, as demonstrated in this paper. The role of aqueous humour in the failure of human trabeculectomies remains to be clarified, and further studies are currently being undertaken to this end.

We gratefully acknowledge the generous financial support provided by the T. F. C. Frost Charitable Trust, the International Glaucoma Association and a Moorfields Endowment Grant.

\section{References}

'Hitchings RA and Grierson I: Clinico pathological correlation in eyes with failed fistulizing surgery. Trans Opthalmol Soc UK 1983, 103: 84-8.

2 Teng CC, Chi HH, Katzin HM: Aqueous degenerative effect and the protective role of endothelium in eye pathology. Am J Ophthalmol 1960, 50: 365-79.

${ }^{3}$ Kornbleuth $\mathrm{W}$ and Tenebaum E: The inhibitory effect of aqueous humour on the growth of cells in tissue culture. Am J Ophthalmol 1956, 42: 70-4.

${ }^{4}$ Herschler J, Claflin AJ, Fiorentino G: The effect of aqueous humor on the growth of subconjunctival fibroblasts in tissue culture and is implications for glaucoma surgery. Am J Ophthalmol 1980; 89: 245-9.

${ }^{5}$ Herschler J: The inhibitory factor in aqueous humor. Vis Res 1981, 21: 163.

${ }^{6}$ Burke J, Foster S, Herschler J: Aqueous humor as a modulator of growth in fibroblast cultures. Curr Eye Res 1983, 2: 835-41.

${ }^{7}$ Radius RL, Herschler J, Claflin A, Fiorentino G: Aqueous humor changes after experimental filtering surgery. Am J Ophthalmol 1980, 89: 250-4.

${ }^{8}$ Miller MH, Joseph NH, Ennis KW, et al.: An animal model of filtration surgery. Trans Ophthalmol Soc UK 1985, 104: 893-97.

${ }^{9}$ Gressel MG, Parrish RK, Folberg R: 5-Flourouracil and glaucoma filtering surgery: I. An animal model. Ophthalmol 1984, 91: 378-83.

1") Freundlich B, Bomalaski JS, Neilson E, Jiminez SA: Regulation of fibroblast proliferation and collagen synthesis by cytokines. Immunol Today 1986, 7: 303-7.

"Boyden S: The chemotactic effect of mixtures of antibody and antigen on polymorphonuclear leukocytes. J Exp Med 1962, 115: 453-66.

12 Postlethwaite AE, Snydermán R, Kang AH: The chemotactic attraction of human fibroblasts to a lymphocyte-derived factor. J Exp Med 1976, 144: 1188-201.

${ }_{13}^{3}$ Ungari S, Katari RS, Alesandri G, Gullino PM: Cooperation between fibronectin and heparin in the mobilization of capillary endothelium. Inv Met 1985, 5: 193-205.

i Senior RM, Griffin GL, Mecham RP: Chemotactic responses of fibroblasts to tropoelastin and elastin-derived peptides. J Clin Invest 1982, 70: 614-8.

15 Mensing H, Pontz BF, Müller PK, Gauss-Müller V: A study on fibroblast chemotaxis using fibronectin and conditioned medium as chemoattractants. Eur J Cell Biol 1983, 29: 268-73.

${ }^{16}$ Postlethwaite AE, Keski-Oja J, Balian G, Kang $\mathrm{AH}$ : Induction of fibroblast chemotaxis by fibronectin. Localization of the chemotactic region to a 140,000-molecular weight non-gelatin-binding fragment. J Exp Med 1981, 153: 494-9.

17 Zigmond SH and Hirsch JG: Leukocyte locomotion and chemotaxis. New methods for evaluation, and demonstration of a cell-derived chemotactic factor. J Exp Med 1973, 137: 387-410.

${ }^{18}$ Grinnell F, Billingham RE, Burgess L: Distribution of fibronectin during wound healing in vivo. $J$ Invest Dermatol 1981, 76: 181-9.

${ }^{14}$ Hynes RO: Fibronectins. Scientific Am July 1983: 32-41.

2" Reid T, Kenney MC, Waring G: Isolation and characterization of fibronectin from bovine aqueous humor. Invest Ophthalmol Vis Sci 1982, 22: 57-61.

2l Seppä HEJ, Yamada KM, Seppä ST, et al.: The cell binding fragment of fibronectin is chemotactic for fibroblasts. Cell Biol Int Rep 1981, 5: 813-9.

22 Albini A, Richter H, Pontz BF: Localization of the chemotactic domain in fibronectin. FEBS 1983, 156: $222-6$.

${ }_{23}$ Postlethwaite AE, Seyer JM, Kang AH: Chemotactic attraction of human fibroblasts to type I, II, and III collagens and collagen-derived peptides. Proc Nat Acad Sci 1978, 75: 871-5.

${ }^{24}$ Senior RM, Griffin GL, Mecham RP, et al.: Val-GlyVal-Ala-Pro-Gly, a repeating peptide in elastin, is chemotactic for fibroblasts and monocytes. $J$ Cell Biol 1984, 99: 870-4.

25 Seppä H, Grotendorst G, Seppä S, et al.: Plateletderived growth factor is chemotactic for fibroblasts. J Cell Biol 1982, 2: 179-201.

${ }_{26}$ Mensing $\mathrm{H}$ and Czarnetzki BM: Leukotriene $\mathrm{B}_{+}$ induces in vitro fibroblast chemotaxis. $J$ Invest Dermatol 1094, 82: 9-12.

${ }^{27}$ Senior RM, Skogen WF, Griffin GL, Wilner GD: Effects of fibrinogen derivatives upon the inflammatory response. Studies with human fibrinopeptide B. J Clin Invest 1986, 77: 1014-9.

2x Wahl SM and Wahl LM: Modulation of fibroblast growth and function by monokines and lymphokines. Lymphokines 1981, 2: 179-201.

${ }^{29}$ Postlethwaite AE, Snyderman R, Kang AH: Generation of a fibroblast chemotactic factor in serum by activation of complement. J Clin Invest 1979 , 64: $1379-85$.

30 Rosenbaum JT, Wong K, Perez HD, et al.: Characterization of endotoxin-induced $\mathrm{C} 5$-derived chemotactic activity in aqueous humor. Invest Ophthalmol Vis Sci 1984, 25: 1184-91. 
${ }^{31}$ Zetter BR, Martin GR, Birdwell CR, Gospodarwicz $D$ : Role of high-molecular weight glycoprotein in cellular morphology, adhesion and differentiation. Ann NY Acad Sci 1978, 312: 299

${ }^{32}$ Worthen DM and Cleveland PH: Fibronectin production by cultured human trabecular meshwork cells. Invest Ophthalmol Vis Sci 1982, 23: 265-9.

${ }^{33}$ Campochiaro PA and Glaser BM: Platelet-derived growth factor is chemotactic for human pigment epithelial cells. Arch Ophthalmol 1985, 103: 576-9.

${ }^{34}$ Rosenbaum JT, Raymond W, Seymour BW, et al.: The effect of corticosteroids or nitrogen mustard on aqueous humor chemotactic acivity induced by intravitreal endotoxin. Clin Immunol Immunopath 1986, 39: 414-20.

${ }^{35}$ Tapper D, Scheimer C, Frissora H, Zetter B: The stimulation of capillary endothelial cell migration by aqueous humor. J Surg Res 1981, 30: 262-8. 